\title{
Explaining standard dominance: The effect of influential network positions and structural holes
}

\author{
Geerten van de Kaa \\ Faculty of Technology, Policy and Management, Delft University of Technology \\ g.vandekaa@tudelft.nl
}

\begin{abstract}
Innovative systems and infrastructures such as smart grids, the internet of things, cities, or highways require generally accepted common compatibility standards to enable components of such systems to interoperate. In some cases, various standards are developed by competing standards organizations, often resulting in standards battles. This paper focuses on factors that affect the outcome of these standards battles, and, specifically, on the effect of an influential position in an industry-wide standards networks and the existence of structural holes in that network on standard dominance. The empirical context is the consumer electronics, telecommunications, and ICT arenas. We conduct a study of 103 standards organizations from 2000 to 2011. We find support for the hypothesis that standards that are supported by standards organizations that have a central position in the industry-wide standards network have a high chance of achieving dominance. Thus, we show that apart from complementary assets and innovation strategies, firms can also adopt specific networking strategies to achieve a successful standard.
\end{abstract}

\section{Introduction}

A market that is characterized by increasing returns to adoption often results in the establishment of a single dominant design. One important underlying reason for this is the existence of network effects, whereby products increase in value the more they are adopted by end users $[1,2]$. Often, in these markets, battles amongst compatibility standards are waged resulting in a 'winner takes all' situation [3]. Standards are essential elements that define technological platforms as when single dominant standards are established, innovations in the form of new platforms may be achieved whereby the compatibility standards act as interfaces that ensure the interoperability of the distinct components. Indeed, as Baldwin and Woodard [4] argue, a system's interfaces as a whole constitute the technological platform.

Examples of standards battles include the battle between AC versus DC current, VHS versus Betamax, Multimedia compact disc versus Super Density Disc, and the more recent Blu-ray versus HD-DVD case [3, 5, 6]. Various scholars have assessed the outcome of these battles by discussing factors for standard dominance [7].

The topic has been studied from multiple angles. Although evolutionary economists argue that standards are established through path dependent mechanisms and firms cannot directly influence the outcome of standards battles [8], industrial economists emphasize the importance of market mechanisms such as pricing mechanisms, and network and bandwagon effects [1, 2]. Technology management scholars borrow from industrial economists and emphasize the importance of quickly building an installed base [3]. They argue that resources (e.g. financial resources or reputation) may enable a standard supporter to devise certain strategies (e.g. timing of entry or marketing) to accumulate installed base [9]. Other scholars approach the topic from a governance perspective [10] or institutional perspective [11]. Recently, weights have been established for factors for standard dominance for a diverse range of contexts including building automation systems and wireless data communication [12-14].

Although studies have illustrated and analyzed the effect of standards network composition on standard dominance $[5,6,15]$, little has been written about the role of the structural characteristics of standards networks on the chances that the standards achieve dominance (exceptions include [16, 17]. We address this gap in the literature and propose that the actors that support the standard, and specifically, their structural position in an industry-wide standards network play an important role in whether this standard will reach dominance in the market. 
Research has shown that networks provide benefits to participants in the network. For example, a firm's competitive position may be enhanced by forming relationships within the network [18, 19]. Networks can provide information and learning benefits to their members [20, 21]. We explore these benefits in the context of standardization. Specifically, we address the question: what is the influence of the structural network position of a standards organization in an industry-wide standards network on the chances that the standard that is promoted by the standards organization achieves dominance?

In this paper, we distinguish between two types of networks; standards organizations and industry-wide standards networks. A standards organization is defined as a collection of actors that develop and/or promote a particular standard. Examples of such standards organizations are standards alliances (such as the WIFI alliance), and standards committees (such as the IEEE802.11 committee). An industrywide standards network is the total set of actors (standards organizations and or firms) in a specific industry, and their relationships. An example is the set of firms involved in standards organizations in the data communication industry and their relations [22].

\section{Theory and Hypotheses}

The literature on social and inter-organizational networks mentions several benefits of establishing inter-organizational relationships in general. Firms can gain access to key assets, resources, and capabilities, and they can improve their strategic position through their relationships with other actors in the network [18, 19]. These benefits may also apply to standards organizations. For example, a standard supporter can provide access to complementary assets [23] that are essential for establishing standard dominance [7]. Such complementary assets include reputation and financial resources [3]. Moreover, by establishing relationships with manufacturers of (key) complementary goods [5], firms can gain control over the availability and supply of these goods. A large availability of complementary goods leads to an increase in installed base and to standard dominance [24, 25]. Furthermore, inter-organizational relationships can lead to collective action and coordination of tasks $[6,26]$, both of which are required to create a successful standard. Interorganizational relationships can provide access to novel information and facilitate learning among actors. In fact, research has indicated that firms participating in standards organizations more frequently use each other's patents [27] increasing innovation output. Firms can also gain access to tacit capabilities [28] or inaccessible knowledge [20] through their network partners.

\subsection{Influential position}

When a standards battle is fought, it mostly occurs between rival standards organizations. For example, in the battle for a high density optical disk standard, Blu-ray battled against HD-DVD. Both standards were promoted by rival standards organizations. Eventually, Blu-ray won which spurred technological innovation in the form of Bluray disc players and gaming consoles, but also in the form of complementary goods (movies, games, etc.) [29]. The presence of large powerful firms in a standards organization is often an incentive for smaller firms to join. They strengthen the organization by increasing available resources and knowledge [23, 30]. Hence, influential firms can convince other firms directly or indirectly to join standards organizations. However, besides being influential in (local) standards organizations, firms can also exert influence in an industry-wide standards network. They may have sufficient resources to participate in multiple standards organizations, and by doing so, assume an influential position in the industry-wide standards network.

First, by taking on an influential position in an industry-wide standards network, firms can gain access to knowledge and information faster and can access multiple short paths to other firms and standards organizations within the industry-wide network. As these members interact with more firms and participate in more organizations, they can also learn from actors and obtain external knowledge [31]. Indeed, it has been argued that a firm's network position positively relates to its innovation output $[32,33]$. As information diffuses through the network from actor to actor, it is important to keep the paths to other firms and organizations short as information is transmitted faster and with more integrity through a network with shorter paths [22, 31]. The electronics market is characterized by rapid technological change and fast changing consumer preferences, and it is therefore important for standards organizations and firms to adapt their standards or products swiftly to keep up with the pace of technological progress and to satisfy consumer needs. Acquiring information before the competition can create a competitive advantage [34]. By implementing this information into the standard, the standard can be adapted to customer needs better and will therefore be more successful [6]. 
Second, by taking on a central and influential position in the network, firms can exert more influence on other actors in the network [33] and can also spread information to other actors more easily [26]. Potential partners can become interested if they receive information about the standard and the organization behind it through their network [35]. As the organization becomes a central point in an industry-wide network, its reach becomes larger, enabling actors to form more partnerships, and enhancing reputation and trust [31]. Through this increased exposure, its actions become more visible, and the organization can better promote the supported standard. The promotion of the standard might persuade supporting firms in other (possibly competing) standards organizations to join the standards organization so that they can use the standard in their own products. These new member firms can implement the standard in their products, thereby increasing the installed base and the number of complementary products and positively influencing the chances of standard dominance [25]. Hence, we posit that the influential position of the members of a standards organization can raise the level of influence of the standards organization, increasing the chances of success of the standard.

Hypothesis 1: A standard that is supported by a standards organization that has a more influential position in an industry-wide standards network has a higher chance of achieving dominance.

\subsection{Structural holes}

All ties can provide information, but ties can become redundant if the same information comes from different ties. Therefore non-redundant ties should be fostered, because they can provide different information more efficiently $[36,37]$. Nonredundant ties exist when there are few connections between separate groups of actors. Due to the limited number of connections between the two groups of actors, the actors in the different groups possess different information. The separations between these groups are called structural holes [36]. Structural holes can be bridged by actors that have ties with both groups. As the different sides of the structural hole hold different information, a bridging actor can create value by combining information [37]. Firms that can successfully bridge these structure holes can serve as an obligatory passage point for information across the structural hole [38]. Firms active in different markets or niches will interact less often than firms active in the same market. Structural holes will therefore likely exist between different markets or niches.

Structural holes may also exist in industry-wide standards networks. The presence of structural holes means that only a few connections between the groups on different sides of the holes exist. Therefore, valuable consumer preference information is not available to other standards organizations, but only to the standards organization that bridges the structural hole. Consequently, this information can result in a competitive advantage for the standards organization that bridges the structural hole as to launch a standard successfully in a new market or niche, information about consumer preferences and the market environment is needed to determine the successful innovation strategy. Furthermore, standards organizations that bridge structural holes and have access to valuable consumer preference information from different markets can use this information to adapt the properties of the standard to consumer demand in multiple markets. This would enable successful launching of the standards in multiple industries, which would increase the potential market size of the standard. Furthermore, by adapting standards to user requirements, more diverse firms will adopt the standard [6]. Launching products implementing the standard in different markets increases the installed base and the number and variety of complementary products, and consequently increases the chances of standard dominance [25]. Therefore we posit:

Hypothesis 2: A standard that is supported by a standards organization that can successfully bridge structural holes in the industry-wide standards network has a higher chance of achieving dominance

\section{Method}

This study uses data on standards, standards organizations, and firms participating in the information technology, consumer electronics and telecommunications market in the period from 2000 to 2011. The data was collected from archived websites of standards organizations (webarchive.com), press archives, and information from databases such as the Lexis-Nexis and Thomson One Banker. Examples of standards battles that were taken into account are USB vs Firewire and WiFi vs HomeRF. These battles were fought in the period 2000-2011. USB and Firewire define data communicatiosn between the PC and peripheral devices and HomeRF and WiFi are standards that 
define wireless data communication. We refer to [39] for a more detailed illustration of these cases.

We represent the standards organizations by the members that participate at the highest strategic level of the organization. These members can actually influence the strategic direction of the organization and the standard as they formally approve the specifications of the standard. In most standards organizations, this is the board of directors. In other standards organizations, it is the equivalent highest organizational level which has the power to vote. The board consists of individuals that represent their organization. This study looks at the firms which these people represent and takes these firms to be board members.

This study uses a sample of 103 standards organizations, which in total constitutes 644 complete observations. As the number of standards organizations is relatively large compared to the average number of observations per standards organizations, the results from this analysis will be efficient and consistent.

Using board membership data, we created a bipartite network of standards organizations and firms. Connections between standards organizations and firms are created through board memberships. We analyzed this network using the program UCInet. As the mathematics used to analyze social networks require square matrices, we converted the rectangular affiliation data matrices to square matrices by calculating the biadjacency matrix; a square matrix of dimensions $M X N$ [40].

The network characteristics are operationalized using centralities which are normalized to enable comparison between the networks. As connections are only possible between the two different types of actors, the maximum number of connections in the biadjacency is lower than the theoretical maximum of an ordinary $M X N$, and therefore a different normalization is necessary which can be calculated using the program UCInet.

We tested the effects of the network characteristics on standard dominance by using Generalized Estimating Equations (GEE). As the database contains data in long format, a regression method that could account for repeated measurements was necessary. GEE was specifically developed to analyze longitudinal data with repeated measurements. It accounts for repeated measurements by determining the average effect of the independent predictor variables on the dependent response variables. In this case, we determined the effects of the network characteristics on standard dominance. Using GEE, we determined the effects averaged out over all standards organizations.

Dependent variable: Standard Dominance. Standard dominance was operationalized by determining the number of firms supporting the standard. To determine the number of supporting firms, we collected the total number of members which we have termed network size. We considered only corporate members and ignored individual members, as the focus of this project is on firms and standards organizations. As network characteristics are not expected to influence network size immediately, the effects of these variables have been lagged by one year. This also partially corrects for standards organizations that have just been founded and have not had time to gain members. As the number of members in standards organizations can differ considerably, the distribution of organization size is non-normal and positively skewed. We therefore transformed the data by taking the logarithm of network size to make the data approximately normal.

Independent variable 1: Influential position. To measure the value of the connections to the board members, we used eigenvector centrality which accounts for both direct and indirect ties. This measure of centrality is positively related to social capital and has been used to estimate the influence of an actor [41]. Eigenvector centrality in bipartite graphs has often been used in studies of interlocking corporate boards to measure the centrality of the actors.

Independent variable 2: Structural holes. To measure the bridging of structural holes for hypothesis 2 , we used betweenness centrality. To calculate betweenness centrality, we calculated all possible shortest paths between nodes. Betweenness centrality measures how many of these shortest paths pass through a node [42]. In the bipartite graph, the theoretical maximum number of shortest paths differs from the one-mode case, hence a different normalization is required. A node that connects structural holes will lie on many of the shortest paths connecting the two sides of the hole; consequently this node will have a high betweenness centrality [40]. Betweenness centrality is highly correlated with structural holes [36] and has been used to measure access to structural holes [26, 43].

Control variable: Year. The intercept for every year is flexible. These flexible intercepts have been fitted using a categorical year variable. This procedure helps to account for exogenous effects such as market or environmental factors. As standards organizations experience similar events and 
a similar environment in the same year, the year could affect the network size in certain years.

\section{Results}

Table 1 shows the descriptive statistics and the correlations between the variables.

Table 1: Descriptive statistics and correlations

\begin{tabular}{lllllll}
\hline Variable & Mean & S.D. & Min & Max & 1 & 2 \\
\hline 1. Log Size & 4.51 & 1.19 & 1.61 & 7.00 & & \\
2. Structural Holes & 0.026 & 0.021 & 0.000 & 0.117 & $0.201^{* *}$ & \\
3. Influential Position & 0.089 & 0.070 & 0.000 & 0.312 & $0.404^{* *}$ & $0.329^{* *}$ \\
\hline$n=644 ; "{ }^{* *} p<0.01$ (two-tailed) & & & & &
\end{tabular}

The resulting regression coefficients with the standard errors are reported in Table 2. In the lower part of this table, two goodness-of-fit indicators have been added. As GEE estimates the parameters under unknown correlation structures, the normal goodnessof-fit indices cannot be used. Instead, the Quasi Likelihood under Independence Model Criterion (QIC) and the Corrected Quasi Likelihood under Independence Model Criterion (QICC) are used. Both these fit indices are extensions of Akaike Information Criterion. Smaller QIC and QICC indicate better model fit.

\begin{tabular}{|c|c|c|c|c|}
\hline Variable & Model 1 & Model 2 & Model 3 & Model 4 \\
\hline Year 2000 & $\begin{array}{l}4.55^{38 z} \\
(0.16)\end{array}$ & $\begin{array}{l}4.18^{2 \times 8 z} \\
(0.23)\end{array}$ & $\begin{array}{l}3.70^{28 z 8} \\
(0.21)\end{array}$ & $\begin{array}{l}3.79^{2 z 8} \\
(0.19)\end{array}$ \\
\hline Year 2001 & $\begin{array}{l}4.45^{* * 8} \\
(0.16)\end{array}$ & $\begin{array}{l}4.11^{* s z} \\
(0.22)\end{array}$ & $\begin{array}{l}3.65^{* * 8} \\
(0.20)\end{array}$ & $\begin{array}{l}3.74^{* * 8} \\
(0.18)\end{array}$ \\
\hline Year 2002 & $\begin{array}{l}4.40^{* * 8} \\
(0.15)\end{array}$ & $\begin{array}{l}4.11^{* 8 z} \\
(0.20)\end{array}$ & $\begin{array}{l}3.69^{* * z} \\
(0.17)\end{array}$ & $\begin{array}{l}3.77^{* * 8} \\
(0.16)\end{array}$ \\
\hline Year 2003 & $\begin{array}{l}4.45^{* * *} \\
(0.15)\end{array}$ & $\begin{array}{l}4.15^{* * *} \\
(0.20)\end{array}$ & $\begin{array}{l}3.79^{* * *} \\
(0.18)\end{array}$ & $\begin{array}{l}3.87^{* * *} \\
(0.17)\end{array}$ \\
\hline Year 2004 & $\begin{array}{l}4.51^{* 2 * 8} \\
(0.16)\end{array}$ & $\begin{array}{l}4.21^{* * x} \\
(0.20)\end{array}$ & $\begin{array}{l}3.83^{* s * 8} \\
(0.19)\end{array}$ & $\begin{array}{l}3.90^{* * z=} \\
(0.18)\end{array}$ \\
\hline Year 2005 & $\begin{array}{l}4.51^{* * z} \\
(0.16)\end{array}$ & $\begin{array}{l}4.23^{* * z} \\
(0.21)\end{array}$ & $\begin{array}{l}3.81^{* * 8} \\
(0.19)\end{array}$ & $\begin{array}{l}3.88^{* * z} \\
(0.18)\end{array}$ \\
\hline Year 2006 & $\begin{array}{l}4.51^{* s *} \\
(0.15)\end{array}$ & $\begin{array}{l}4.23^{* * *} \\
(0.20)\end{array}$ & $\begin{array}{l}3.82^{* * *} \\
(0.18)\end{array}$ & $\begin{array}{l}3.89^{* * * *} \\
(0.18)\end{array}$ \\
\hline Year 2007 & $\begin{array}{l}4.63^{* * s} \\
(0.15)\end{array}$ & $\begin{array}{l}4.31^{* * x} \\
(0.21)\end{array}$ & $\begin{array}{l}3.92^{* * x} \\
(0.19)\end{array}$ & $\begin{array}{l}4.00^{* z x} \\
(0.18)\end{array}$ \\
\hline Year 2008 & $\begin{array}{l}4.48^{* * *} \\
(0.16)\end{array}$ & $\begin{array}{l}4.17^{* * *} \\
(0.22)\end{array}$ & $\begin{array}{l}3.79^{* * *} \\
(0.20)\end{array}$ & $\begin{array}{l}3.88^{* * *} \\
(0.18)\end{array}$ \\
\hline Year 2009 & $\begin{array}{l}4.52^{z s z} \\
(0.16)\end{array}$ & $\begin{array}{l}4.18^{* z z} \\
(0.22)\end{array}$ & $\begin{array}{l}3.88^{* z z} \\
(0.19)\end{array}$ & $\begin{array}{l}3.93^{* * z} \\
(0.18)\end{array}$ \\
\hline Year 2010 & $\begin{array}{l}4.57^{* z z} \\
(0.16)\end{array}$ & $\begin{array}{l}4.26^{* z z} \\
(0.21)\end{array}$ & $\begin{array}{l}3.88^{z * z} \\
(0.19)\end{array}$ & $\begin{array}{l}3.96^{* z *} \\
(0.18)\end{array}$ \\
\hline Structural Holes & & $\begin{array}{l}11.75^{*} \\
(4.89)\end{array}$ & $\begin{array}{l}4.54 \\
(4.92)\end{array}$ & \\
\hline Influential Position & & & $\begin{array}{l}6.66^{* * z} \\
(1.45)\end{array}$ & $\begin{array}{l}7.00^{* z s} \\
(1.26)\end{array}$ \\
\hline QIC & 931.0 & 902.3 & 788.3 & 783.0 \\
\hline Difference in QIC & & -28.7 & -142.7 & -148.0 \\
\hline QICC & 931.1 & 894.5 & 773.5 & 776.6 \\
\hline Difference in QICC & & -36.6 & -157.6 & -154.5 \\
\hline
\end{tabular}

Model 2, which includes structural holes but without influential position, resulted in a positive and significant regression weight for structural holes. However, adding influential position removed this significant effect. This change in regression weight could be a sign of multicollinearity. This is also suggested by the correlations in Table 1, which show that influential position and structural holes are significantly correlated. We also tested a fourth model, which does not include structural holes. This model resulted in positive and significant regression weight for influential position at a lower QIC score but at a higher QICC score. Therefore, it cannot be indisputably determined whether this model is an improvement over Model 3.All models that include influential position result in positive and significant regression weights, even at a very high confidence interval. Furthermore, we can conclude from the QIC and QICC scores that adding influential position results in a better fitting model than the variable intercept baseline model.

Therefore, we find support for the positive effects of the influential position of the standards organization in the network on the success of the standards organization and find support for Hypothesis 1. This implies that successful standards organizations are positioned in an influential position in the network of standards organizations and firms. For hypothesis 2, the effect of structural holes in the industry-wide standards network on standard dominance, we found insufficient support. It should be remarked that the literature on structural holes has reached no consensus on the effects of structural holes. One school of thought formed by Burt and others proposes that value can be created if structural holes are bridged [36, 37]. Another school of thought emphasizes the trust generation function of networks. A network without structural holes facilitates the generation of trust. As all actors are connected to each other, opportunistic behavior can be punished through collective action [44]. Following this line of thought, one would assume that a network with structural holes would be less efficient in sharing information. Standards organizations that bridge structural holes may be faced with members that do not trust each other, which would negatively affect the performance of the standard. Ahuja [37] also finds evidence for the negative effects of structural holes. As evidence for both schools of thought has been found, it is possible that bridging structural holes might affect the standards organization both positively and negatively. Hence, the total effect of bridging structural holes may indeed be zero.

\section{Discussion and Conclusion}

This paper focuses on factors that affect the outcome of standards battles. We have studied the 
influence of structural aspects of industry-wide standards networks on standard dominance. We have analyzed data from a dataset consisting of standards, standards organizations, and firms participating in these organizations, covering the period from 2000 to 2011. We found that a standards organization's influential position in an industry-wide standards network positively affects the chances that its standard achieves dominance. This is one of the first studies that relates structural network characteristics to standard dominance. So, for a standards organization that is developing and promoting standards for e.g. the internet of things it is important to have an influential position in the industry-wide standards network as it then has a higher chance of achieving success with its standard.

This research has several theoretical implications For innovation management in general and standards and dominant designs in particular. First, although the effect of the composition of standards networks in relation to standard dominance has been researched in several case studies of standards battles [5, 6], we focus on the effect of network structure on standard dominance; a topic that has been scarcely studied. Secondly, longitudinal studies of standards networks are lacking (one exception is Soh [33]). Our study covers the period 2000-2011 and takes into account the various changes that took place in the industrywide standards network during this period. Third, the effect of a standards organization's influential position in an industry-wide standards network on standard dominance has not been studied before. We show that a standards organization's influential position in an industry-wide network positively affects the chances that its standard achieves dominance. Finally, this study provides additional support for the notion that the outcome of standards battles is not fully characterized by path dependency, but that standard supporters can influence the outcome. This is in line with results from prior studies [24].

This research also has managerial implications. Our results imply that support from influential firms is needed to achieve a successful standard. Earlier research has already indicated that firms with good reputation and sales affect the success of standards [45]. Our study indicates that besides these static resources, it is important for a standards organization to have members that are active in an industry-wide network. To a certain extent, these effects will accompany each other as powerful and influential firms produce many products and therefore have incentives to join many standards organizations. In our findings, we see that the firms scoring the highest on eigenvector centrality, used to measure influential position, are well-known companies who are industry leaders (examples are Dell, Intel, Microsoft, Samsung, and Sony). Firms that develop standards for e.g. the internet of things should actively involve these industry leaders early in the standardization process as they can exert influence in an industrywide standards network.

A limitation is that all ties of the industry-wide network have been modeled as being equally strong. Although all firms in the board can participate in the decision making of the standards organization, some firms might be more influential in this process. Large firms or firms with specific capabilities and assets might be able to exert more influence on the development of the standard. Firms may participate in the board of multiple standards organizations, but their activity in these boards could differ. For example, firms might be more actively involved in a standards organization when the standard is more important to the firm. Future research could attempt to model these ties as ties of different strength. This information, however, is often not available. Even if this information was available, it would be difficult to use as many network measures do not exist for valued networks [40]. Another limitation is related to the operationalization of standard dominance in terms of the number of firms. Future research could attempt to measure standard dominance more precise by incorporating the size of the firms or even incorporating the consumer perspective and effectively operationalize standard dominance in terms of market share per standard. Furthermore, we focus on firms and standards organizations that are active in the telecommunications, information technology, and consumer electronics industry. The question arises whether the results of our study are specific for these particular industries or whether similar results might apply for other industries. Future research could explore this in more depth. Finally, this study focuses on network structural characteristics and their effect on standard dominance. Future research could study the effect of other aspects of the network that might affect standard dominance such as its composition, the strength of ties between actors within a standards organization (in terms of e.g. the number of repeated interactions), attunement or coordination in the standards organization.

\section{References}

[1] J. Farrell and G. Saloner, "Standardization, compatibility, and innovation," The Rand Journal of Economics, vol. 16, pp. 70-83, 1985. 
[2] M. L. Katz and C. Shapiro, "Network externalities, competition, and compatibility," American Economic Review, vol. 75, pp. 424-440, 1985.

[3] C. Shapiro and H. R. Varian, Information rules, a strategic guide to the network economy. Boston, Massachusetts: Harvard Business School Press, 1999.

[4] C. Y. Baldwin and C. J. Woodard, "The architecture of platforms: a unified view," in Platforms, markets and innovation, A. Gawer, Ed., ed Celtenham, UK: Edwar Elgar Publishing, 2009, pp. 19-44.

[5] M. A. Cusumano, Y. Mylonadis, and R. S. Rosenbloom, "Strategic maneuvering and mass-market dynamics: the triumph of VHS over Beta," Business History Review, vol. 66, pp. 51-94, 1992.

[6] J. Van den Ende, G. Van de Kaa, S. Den Uyl, and H. De Vries, "The paradox of standard flexibility: the effects of co-evolution between standard and interorganizational network," Organization Studies, vol. 33, pp. 705-736, 2012.

[7] F. F. Suarez, "Battles for technological dominance: An integrative framework," Research Policy, vol. 33, pp. 271286, 2004.

[8] W. B. Arthur, "Competing technologies, increasing returns, and lock-in by historical events," The Economic Journal, vol. 99, pp. 116-131, 1989.

[9] S. R. Gallagher and S. H. Park, "Innovation and competition in standard-based industries: a historical analysis of the U.S. home video game market," IEEE Transactions on Engineering Management, vol. 49, pp. 6782, 2002.

[10] G. Van de Kaa and J. A. De Bruijn, "Platforms and incentives for consensus building on complex ICT systems: the development of WiFi," Telecommunication Policy, vol. 39, pp. 580-589, 2015.

[11] G. Van de Kaa, M. Greeven, and G. van Puijenbroek, "Standards battles in China: opening up the black-box of the Chinese government," Technology Analysis \& Strategic Management, vol. 25, pp. 567-581, 2013.

[12] G. Van de Kaa, H. J. De Vries, and J. Rezaei, "Platform Selection for Complex Systems: Building Automation Systems," Journal of Systems Science and Systems Engineering, vol. 23, pp. 415-438, 2014.

[13] G. Van de Kaa, J. Rezaei, L. Kamp, and A. De Winter, "Photovoltaic Technology Selection: A Fuzzy MCDM Approach," Renewable and Sustainable Energy Reviews, vol. 32, pp. 662-670, 2014.

[14] G. Van de Kaa, H. W. G. M. Van Heck, H. J. De Vries, J. C. M. Van den Ende, and J. Rezaei, "Supporting Decision-Making in Technology Standards Battles Based on a Fuzzy Analytic Hierarchy Process," IEEE
Transactions on Engineering Management, vol. 61, pp. 336-348, 2014.

[15] G. Van de Kaa, J. Van den Ende, and H. J. De Vries, "Strategies in network industries: the importance of interorganisational networks, complementary goods, and commitment," Technology Analysis \& Strategic Management, vol. 27, pp. 73-86, 2015.

[16] A. Afuah, "Are network effects really all about size? The role of structure and conduct," Strategic Management Journal, vol. 34, pp. 257-273, 2013.

[17] D. P. McIntyre and M. Subramaniam, "Strategy in network industries: A review and research agenda," Journal of Management, vol. 35, pp. 1494-1517, 2009.

[18] K. Eisenhardt and C. Schoonhoven, "Resource-based view of strategic alliance formation: Strategic and social effects in entrepreneurial firms " Organization science, vol. 7, pp. 136-150, 1996.

[19] M. E. Porter and M. B. Fuller, "Coalitions and global strategy," in Competition in global industries, M. E. Porter, Ed., ed Boston: Harvard Business University Press, 1986, pp. 315-343.

[20] G. Hamel, "Competition for Competence and Interpartner Learning within International Strategic Alliances," Strategic Management Journal, vol. 12, pp. 83-103, 1991.

[21] G. Hamel, Y. Doz, and C. Prahalad, "Collaborate with your competitors and win," Harvard business review, vol. january / february, pp. 133-139, 1989.

[22] P.-H. Soh and E. B. Roberts, "Networks of innovators: a longitudinal perspective," Research Policy, vol. 32, pp. 1569-1588, 2003.

[23] D. J. Teece, "Profiting from technological innovation: implications for integration, collaboration, licensing, and public policy," Research Policy, vol. 15, pp. 285-305, 1986.

[24] M. A. Schilling, "Technology success and failure in winner-take-all markets: the impact of learning orientation, timing, and network externalities.," Academy of Management Journal, vol. 45, pp. 387-398, 2002.

[25] J. Cenamor, B. Usero, and Z. Fernandez, "The role of complementary products on platform adoption: Evidence from the video console market," Technovation, vol. 33, pp. 405-416, 2013.

[26] K. G. Provan, A. Fish, and J. Sydow, "Interorganizational networks at the network level: A review of the empirical literature on whole networks," Journal of management, vol. 33, pp. 479-516, 2007.

[27] H. Delcamp and A. E. Leiponen, "Innovating standards through informal consortia: The case of wireless telecommunications," International Journal of Industrial Organization, vol. 36, pp. 36-47 2014. 
[28] P. J. Lane and M. Lubatkin, "Relative Absorptive Capacity and Interorganizational Learning," Strategic Management Journal, vol. 19, pp. 461-478, 1998.

[29] S. R. Gallagher, "The battle of the blue laser DVDs: The significance of corporate strategy in standards battles," Technovation, vol. 32, pp. 90-98, 2012.

[30] R. Axelrod, W. Mitchell, R. E. Thomas, D. S. Bennett, and E. Bruderer, "Coalition Formation in Standard-Setting Alliances," Management Science, vol. 41, pp. 1493-1508, 1995.

[31] W. W. Powel, K. Koput, and L. Smith-Doerr, "Interorganizational collaboration and the locus of innovation: networks of learning in biotechnology," Administrative Science Quarterly, vol. 41, pp. 116-145, 1996.

[32] G. Ahuja, "Collaboration networks, structural holes, and innovation: A longitudinal study," Administrative Science Quarterly, vol. 45, pp. 425-455, 2000.

[33] P.-H. Soh, "Network Patterns and Competitive Advantage before the Emergence of a Dominant Design," Strategic Management Journal, vol. 31, pp. 438-461, 2010.

[34] D. L. Deeds and C. W. L. Hill, "Strategic alliances and the rate of new product development: An empirical study of entrepreneurial biotechnology firms," Journal of Business Venturing, vol. 11, pp. 41-55, 1996.

[35] R. Gulati, "Network location and learning: The influence of network resources and firm capabilities on alliance formation " Strategic Management Journal, vol. 20, pp. 397-420, 1999.

[36] R. S. Burt, Structural Holes, The Social Structure of Competition. Cambridge, Massachusetts: First Harvard University Press, 1992.

[37] R. S. Burt, "Structural Holes and Good Ideas," American Journal of Sociology, vol. 110, pp. 349-399, 2004.

[38] L. Rosenkopf and M. L. Tushman, "The Coevolution of Community Networks and Technology: Lessons from the Flight Simulation Industry," Industrial and Corporate Change, vol. 7, pp. 311-346, 1998.

[39] G. Van de Kaa and H. De Vries, "Factors for winning format battles: a comparative case study," Technological Forecasting \& Social Change, vol. 91, pp. 222-235, 2015.

[40] J. Scott, Social Network Analysis: A Handbook: Sage Publications Ltd, 2000.

[41] P. Bonacich, "Some unique properties of eigenvector centrality," Social Networks, vol. 29, pp. 555-564, 2007.

[42] L. C. Freeman, "Centrality in social networks conceptual clarification," Social Networks, vol. 1, pp. 215239, 1979.
[43] V. Gilsing, B. Nooteboom, W. Vanhaverbeke, G. Duysters, and A. van den Oord, "Network embeddedness and the exploration of novel technologies: Technological distance, betweenness centrality and density," Research Policy, vol. 37, pp. 1717-1731, 2008.

[44] J. S. Coleman, "Social capital in the creation of human capital," American Journal of Sociology, vol. 94, pp. S95S120, 1988.

[45] F. F. Suarez and J. M. Utterback, "Dominant designs and the survival of firms," Strategic Management Journal, vol. 16, pp. 415-430, Sep. 1995. 